\title{
Perceived barriers and facilitators to participating in the North Carolina Healthy Food Small Retailer Program: a mixed-methods examination considering investment effectiveness
}

\author{
Kathryn A Boys ${ }^{1, *}$ (D), Lindsey Haynes-Maslow ${ }^{2}$, Jared T McGuirt ${ }^{3}$, Alice S Ammerman ${ }^{4}$, \\ Erin E Van Fleet ${ }^{1}$, Nevin S Johnson ${ }^{5}$, Casey J Kelley ${ }^{5}{ }_{(\mathbb{D}}$, Victoria E Donadio ${ }^{5}$, \\ Sheila E Fleischhacker ${ }^{6}$, Kimberly P Truesdale ${ }^{4}$, Ronny A Bell ${ }^{7}$ and \\ Stephanie B Jilcott Pitts 5 \\ 'Department of Agricultural \& Resource Economics, North Carolina State University, 4306 Nelson Hall, Campus Box \\ 8109, Raleigh, NC 27695-8109, USA: ${ }^{2}$ Department of Agricultural \& Human Sciences, North Carolina State \\ University, Raleigh, NC, USA: ${ }^{3}$ Department of Nutrition, University of North Carolina Greensboro, Greensboro, NC, \\ USA: ${ }^{4}$ Department of Nutrition, Gillings School of Global Public Health, University of North Carolina at Chapel Hill, \\ Chapel Hill, NC, USA: ${ }^{5}$ Department of Public Health, East Carolina University, Greenville, NC, USA: ${ }^{6}$ Georgetown \\ University Law Center, Washington, DC, USA: ${ }^{7}$ Department of Social Sciences and Health Policy, Division of Public \\ Health Sciences, Wake Forest School of Medicine, Winston-Salem, NC, USA
}

Submitted 3 November 2020: Final revision received 27 August 2021: Accepted 6 September 2021: First published online 13 September 2021

\begin{abstract}
Objective: The North Carolina Legislature appropriated funds in 2016-2019 for the Healthy Food Small Retailer Program (HFSRP), providing small retailers located in food deserts with equipment to stock nutrient-dense foods and beverages. The study aimed to: (1) examine factors facilitating and constraining implementation of, and participation in, the HFSRP from the perspective of storeowners and (2) measure and evaluate the impact and effectiveness of investment in the HFSRP. Design: The current analysis uses both qualitative and quantitative assessments of storeowner perceptions and store outcomes, as well as two innovative measures of policy investment effectiveness. Qualitative semi-structured interviews and descriptive quantitative approaches, including monthly financial reports and activity forms, and end-of-programme evaluations were collected from participating HFSRP storeowners.

Setting: Eight corner stores in North Carolina that participated in the two cohorts (2016-2018; 2017-2019) of the HFSRP.

Participants: Owners of corner stores participating in the HFSRP.

Results: All storeowners reported that the HFSRP benefitted their stores. In addition, the HFSRP had a positive impact on sales across each category of healthy food products. Storeowners reported that benefits would be enhanced with adjustments to programme administration and support. Specific suggestions included additional information regarding which healthy foods and beverages to stock; inventory management; handling of perishable produce; product display; modified reporting requirements and a more efficient process of delivering and maintaining equipment.

Conclusions: All storeowners reported several benefits of the HFSRP and would recommend that other storeowners participate. The barriers and challenges they reported inform potential approaches to ensuring success and sustainability of the HFSRP and similar initiatives underway in other jurisdictions.
\end{abstract}

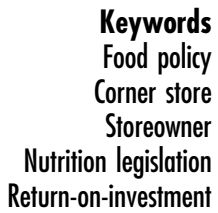

Residents living in communities characterised as rural, lowincome or with high percentages of racial/ethnic minorities are more likely to experience food insecurity and diet-related diseases ${ }^{(1-4)}$. This is partially attributed to limited access to food retailers that sell healthy foods and beverages ${ }^{(5-7)}$. In rural, low-income areas, small food stores 
may be the only retailer available ${ }^{(8,9)}$. Some studies indicate residents often purchase less healthy foods and beverages from these smaller retailers compared with full-sized, chain grocery stores $^{(10,11)}$. Thus, healthy corner store (HCS) initiatives aimed to improve the availability of healthy foods and beverages in small food stores (including corner and convenience stores) have been proposed as an approach to help reduce food insecurity and diet-related diseases ${ }^{(12,13)}$. Recognising this, a number of states, including California, North Carolina (NC), Mississippi, and Oklahoma, have adopted legislation aimed at improving healthy food access through facilitating sales of healthier food and beverage products by small retailers ${ }^{(9,14)}$. These initiatives vary considerably in their scope and approaches used to incentivise store participation.

Research efforts to examine the impact of HCS programmes find these programmes generally improve consumer dietary intention ${ }^{(15)}$ and increase availability of healthier foods and beverages ${ }^{(16,17)}$; the evidence is mixed concerning consumer dietary improvement ${ }^{(8,11,17)}$. In addition to generating several types of demonstrable benefits for consumers, the longer-term success of these programmes also requires longer-term participation of corner stores. To date, relatively few studies have examined the experiences and impacts of participating in HCS initiatives from the perspective of corner storeowners. Additionally, most studies have not quantitatively considered the health impacts generated by programme investments. In the USA, most studies on this topic are qualitative and have focused on store willingness to stock healthier foods ${ }^{(18)}$ as well as the challenges and opportunities associated with doing so ${ }^{(19-21)}$.

Among these studies, none have examined the resource requirements, or attempted to quantify the sales and other financial impacts of HCS initiatives from the perspective of corner storeowners. These insights are important because if corner stores do not reap a positive (and sufficiently large) net benefit from HCS initiatives, they may opt not to enter or, once engaged, may opt to withdraw from these programmes. Therefore, the objectives of the current study are twofold. First, from the perspective of storeowners, the current study identifies and examines factors facilitating and constraining implementation of and store participation in the Healthy Food Small Retailer Program (HFSRP). Second, the current study considers the aggregate impact of this programme by measuring and evaluating the impact and effectiveness of public investment in the HFSRP. To do so, the current analysis uses both qualitative and quantitative assessments of storeowner perceptions and store outcomes, as well as two innovative measures of policy investment effectiveness.

\section{Methods}

\section{Study setting}

The HFSRP was established to provide funding and assistance for small retailers to increase the sales of fresh fruits, vegetables and other nutrient-dense foods at affordable prices, with the aim to improve the diets of local residents, especially in United States Department of Agriculture (USDA) defined food desert areas ${ }^{(22)}$. Beginning in 2016, small retailers were eligible to apply for grants up to US $\$ 25000$ to reimburse the purchase and installation of refrigeration equipment, display shelving and other equipment necessary for stocking nutrient-dense foods and beverages, including fruits and vegetables, whole grains, nuts, seeds, beans and legumes, low-fat dairy products, lean meats and seafood ${ }^{(22)}$. Funding for the HFSRP is legislatively appropriated; US\$250 000 was allocated to this programme each year (2016-2019).

The NC Department of Agriculture and Consumer Services (NCDA\&CS) serves as the HFSRP implementing agency. This programme is limited to small $(<3000$ square feet) food retail stores that are located in USDA defined food deserts. In addition, stores accepted to the HFSRP must accept or agree to accept Supplemental Nutrition Assistance Program (SNAP) benefits and accept or agree to apply to accept Special Supplemental Nutrition Program for Women, Infants, and Children (WIC) benefits. In its inaugural year (2016-2017), six retailers received a total of US\$124014 in funding. At the time of this writing, three of five stores in the second cohort (2017-2019) had received their equipment which together was valued at US\$34 $946^{(23)}$. It is also worth noting that level of actual spending for each cohort was less than the amount available.

\section{Healtby Food Small Retailer Program stores - participation and data overview}

Stores selected to participate in the HFSRP were admitted on a rolling basis through an application process that was open to all North Carolina corner stores. A widely distributed call for proposals was made at the beginning of each proposal cycle. In addition, community partners assisted in identifying perspective stores. The USDA Food Desert Atlas was used to determine if applicants were located in a food desert ${ }^{(24)}$.

In recruiting stores to participate in the current study, staff of the NCDA\&CS initially reached out to the HFSRP stores to make them aware of this initiative. This contact was followed up by a call from a project team member to provide additional information and to inquire about their willingness to participate in the current study. In the first cohort, six stores were initially enrolled. One store permanently closed during their participation in the HRSRP (insufficient profit) and is not included in the current analysis. As such, five stores in the first cohort (started 2016-2017) and three stores in the second cohort (started 2017-2018) that had installed and were using their equipment at the time of data collection were considered in the current study. Multiple complementary sources of qualitative and quantitative data were collected and analysed including: 
Table 1 Summary of data available for analysis for each participating site

\begin{tabular}{lccccc}
\hline \multicolumn{5}{c}{ Data source } \\
\cline { 3 - 6 } & & \multicolumn{5}{c}{$\begin{array}{c}\text { Monthly } \\
\text { financial } \\
\text { reports and } \\
\text { Store } \\
\text { code }\end{array}$} & Cohort & $\begin{array}{c}\text { Storeowner } \\
\text { interview }\end{array}$ & $\begin{array}{c}\text { End of } \\
\text { activity forms } \\
\text { evaluation }\end{array}$ & HEI \\
\hline S1 & 1 & $\checkmark$ & $\checkmark$ & $\checkmark$ & $\checkmark$ \\
S2 & 2 & $\checkmark$ & $\checkmark$ & $\checkmark$ & COnS \\
S3 & 1 & $\checkmark$ & $\checkmark$ & $\checkmark$ & $\checkmark$ \\
S4 & 2 & $\checkmark$ & $\checkmark$ & $\checkmark$ & $\checkmark$ \\
S5 & 1 & $\checkmark$ & $\checkmark$ & $\checkmark$ & COM \\
S6 & 1 & $\checkmark$ & $\checkmark$ & & $\checkmark$
\end{tabular}

HEI, Healthy Eating Index; HFS, Healthy Food Supply.

Cohort 1 stores joined the Healthy Food Small Retailer Program between 2016 and 2017, and Cohort 2 stores joined between 2017 and 2018.

(1) semi-structured interviews with storeowners; (2) monthly financial reporting and activity forms; (3) endof-programme evaluations; (4) health indices of the Healthy Food Supply (HFS) scores and (5) Healthy Eating Index (HEI-2010) estimates for seven of the eight stores. Interviews and data required for HFS and HEI scores (data sources 1, 4) were collected through an external evaluation of the HFSRP. Monthly financial reports and end-of-programme evaluations (data sources 2, 3) were required to be submitted to the NCDA\&CS by HFSRP stores.

As summarised in Table 1, the data available for each HFSRP site varied. This is due to differences in equipment installation dates, the number of monthly reports submitted and storeowners' willingness to participate in research activities (storeowner interviews, allow their customers to be interviewed). In addition, as Cohort 2 stores had not yet completed their 2-year HFSRP commitment at the time of data collection, end-of-programme evaluations were not available for these sites.

\section{Qualitative data collection and analysis}

Semi-structured interviews with the owners of corner stores participating in the HFSRP were conducted between June and July 2019. An interview guide was developed including questions related to characteristics of the owners, stores and customers, attempts to stock and promote healthier foods and beverages before and after the HFSRP, experiences applying for the HFSRP, time and cost related to applying for and implementing the HFSRP and perceived benefits and challenges related to participating in the HFSRP. Categorical options were used to collect information regarding the stores' yearly sales. Participants were also asked their sex, age, race, highest grade of school completed, annual household income, number of employees and sales volume of the store. The interview guide was reviewed and approved by the East Carolina University Institutional Review Board (IRB); other collaborating institutions this as the IRB approval of record.

Eligibility criteria for interviewees included being the owner or manager of a HFSRP store, able to speak and read English and over 18 years of age. Participants read a consent form, asked any study-related questions, and if they agreed to participate, they signed an informed consent form. Interviews were conducted either by the

study principal investigator or a trained graduate research assistant. On average, each interview lasted $57 \mathrm{~min}$. Participants received a US\$20 gift card upon interview completion.

Interviews were audio recorded and uploaded to Rev.com ${ }^{(25)}$ for transcription. To begin analysis, trained members of the research team read two interviews and independently created codebooks with themes, specific topics, and operational definitions. The study team then met to reconcile the codebooks and create a consensus codebook. Each interview was independently doublecoded by two members of the research team who then met to reconcile and reach consensus concerning the coding of each transcript. Transcripts were then uploaded into NVivo (Version 12, QSR International, Melbourne, Australia) and the finalised coding entered for data analysis and management. Coded transcripts were then reviewed to identify useful quotes for each specific topic.

\section{Monthly financial and activity reports}

HFSRP sites were requested to submit monthly reports to the NCDA\&CS for 2 years following the installation of their equipment. In these reports, owners were asked to provide either the total amount of their own purchases (cost) or the total amount of healthy foods they had sold (revenue) across six product categories: low-fat dairy, whole milk (purchased/sold as part of WIC), whole grains, protein (lean meat, beans, and nuts), fruit (fresh and frozen) and vegetables (fresh and frozen). These reports also asked storeowners about which products were selling well and not well, which vendors were being used and any efforts used to promote healthy products.

Using this information, the average monthly store purchases or revenue for each category of goods were estimated. In addition, one store submitted information regarding both their purchase costs and sales revenue. In this case, price markups, the difference between the selling price and the cost, expressed as a percentage over the cost, were also estimated by category.

\section{End-of-programme evaluations}

NCDA\&CS program evaluations included storeowner assessment of the level of difficulty or satisfaction concerning several aspects of the HFSRP, and their perceptions of programme participation on store sales, provision of healthy foods and customers. This information was 
collected using five-point Likert scales. To summarise these data, the scale values were assigned numeric values that were used to generate descriptive statistics. By way of example, storeowner opinions concerning the difficulty of utilising services provided by the NCDA\&CS were assigned values of: Very Easy (1); Easy (2); Somewhat Difficult (3); Difficult (4) and Very Difficult (5).

\section{Impact of the Healthy Food Small Retailer Program on} bealthy food supply and consumer purchases

The impact of the HFSRP on changes in the availability of healthy foods and customer purchases of healthy foods was also evaluated. The HFS score was used to summarise the availability, price, quality and variety of foods and beverages in each store. HFS scores range from 0 to 31 with higher scores indicating that healthier items are more available, less expensive and higher quality ${ }^{(26,27)}$. The HEI is a valid indicator of whether a diet or food source is consistent with federal dietary guidelines ${ }^{(28-30)}$ and was used to assess the healthfulness of food store purchases. A previous evaluation of the HFSRP calculated HFS and HEI scores for the participating HFSRP stores ${ }^{(23)}$. Using data from the current analysis, the changes in these scores between a baseline period and 1 year after joining the HFSRP were calculated. These results and data provided by the NCDA\&CS concerning the amount of HFSRP funds spent per store ${ }^{(24)}$ (summarised in Table 1) were used to generate a measure of the effectiveness of HFSRP investment on these healthrelated measures. Investment effectiveness was estimated as the change in HFS (or HEI) per US $\$ 1000$ HFSRP investment in the year following the programme implementation. Given gaps in store reporting, it was only possible to evaluate this impact on HFS and HEI for four and five stores, respectively.

\section{Incorporating multiple types and sources of data}

The multiple sources of data used in the current study were used to develop a more complete understanding of the characteristics, insights and impacts of this programme on each store. The information collected through the multiple sources of data used in the current study were not duplicative; as such, it was not the intent nor possible to compare or contrast information collected across sources. Rather, each type of data offers different and complimentary information which, when considered together, permits a richer and more holistic understanding of the impacts of this intervention and permits a variety of measures to be calculated (i.e. investment effectiveness). The following discussion and tables of results draw upon findings from across these different data sources. As an example, characteristics of respondents and participating stores were drawn from the store owner interviews. Results concerning the impacts on stores and opinions of storeowners of participating in the HFSRP draws upon all of the data sources used in this current analysis (summarised in Table 1).

\section{Results}

Characteristics of the respondents and the participating stores are provided in Table 2 . All respondents were storeowners with a mean age of 55 years and a majority were female. These storeowners reported working in their HFSRP stores for an average of $10 \cdot 7$ years and $67 \cdot 0 \mathrm{~h} /$ week. There was considerable variation in the number of store employees; on average, each store had $3 \cdot 3$ full-time and 3.2 part-time staff. Among the stores that provided this information, there was significant variability in their responses ranging from less than US\$250 000 (two stores), to over US\$1 million (one store). The remaining stores indicated that they did not know their annual sales.

\section{Store purchases and sales of bealtby foods by product category}

Data from monthly financial reports, including the average and percent change from stores' baseline spending on items for resale and store revenue by product category, are summarised in Table 3. Participation in the HFSRP had a marked impact on which healthy foods stores opted to stock. In particular, stores reported adding or expanding their offerings of low-fat dairy products, whole grain breads, several sources of protein, and $100 \%$ fruit juices due to the programme. The specific healthy items which sold and did not sell well varied significantly by store and were largely shaped by the needs of the customers who frequent each store. The popularity of healthy food items varied by store; indeed, in the case of wraps, different stores reported this item as selling both particularly well and not well.

In the one case where sufficient data were provided to estimate price markups (margins), wide variation was found across product categories. Positive earnings were made on sales of low-fat dairy $(16.4 \%)$, whole milk $(69 \cdot 1 \%)$ and whole grains $(72 \cdot 1 \%)$. This store, however, experienced a net loss on sales of proteins (-67.4\%), fruit $(-4.3 \%)$, vegetables $(-3.6 \%)$, and $100 \%$ juice $(-29.7 \%)$. It is likely that the higher perishability of these latter products and, in the case of $100 \%$ juice, waste due to low sales accounted for these losses.

\section{Benefits and challenges of Healtby Food Small Retailer Program participation}

Key benefits and challenges experienced by HFSRP stores were related to equipment, stocking healthier foods, working with healthy food suppliers, promoting healthier foods to customers and administration of the HFSRP.

\section{Equipment}

While the particular equipment varied, each store received at least one refrigerator or freezer unit. Programme funds were also used to purchase deli racks, baskets, signage, display cases and shelving. Storeowners appreciated 
Table 2 Characteristics of store owners and stores participating in the North Carolina Healthy Food Small Retailer Program ( $n$ 7)

\begin{tabular}{|c|c|c|c|}
\hline Characteristic & Value mean & SD & Range \\
\hline \multicolumn{4}{|l|}{ Respondent characteristics } \\
\hline Age (years) & 55 & 13.4 & $36-71$ \\
\hline \multicolumn{4}{|l|}{ Sex } \\
\hline Female & 6 & & \\
\hline \multicolumn{4}{|l|}{ Race } \\
\hline White & 2 & & \\
\hline Black or African American & 3 & & \\
\hline American Indian or Alaska Native & 1 & & \\
\hline Asian or Asian American & 1 & & \\
\hline \multicolumn{4}{|l|}{ Education } \\
\hline Some High School & 1 & & \\
\hline High School Graduate/GED & 1 & & \\
\hline Associate's Degree & 1 & & \\
\hline College Graduate & 4 & & \\
\hline Storeowner/co-owner & 7 & & \\
\hline Years worked in store & $10 \cdot 7$ & $8 \cdot 1$ & $2-24$ \\
\hline Hours per week work in store & $67 \cdot 0$ & $24 \cdot 1$ & $25-90$ \\
\hline \multicolumn{4}{|l|}{ Store characteristics } \\
\hline Number of full-time staff* & $3 \cdot 3$ & 3.0 & $1-8$ \\
\hline Number of part-time staff* & $3 \cdot 2$ & $2 \cdot 2$ & $1.5-8$ \\
\hline Annual sales (US\$1000)* & 417 & 257 & $125-750$ \\
\hline Distance to nearest grocery store (miles) & 8.9 & $7 \cdot 0$ & $1.0-20.9$ \\
\hline Funding provided by the HFSRPt & US\$19 476 & $\$ 3785$ & $\$ 14958-\$ 25000$ \\
\hline
\end{tabular}

GED, graduate equivalency degree; HFSRP, Healthy Food Small Retailer Program.

${ }^{*}$ Respondents were provided an option to answer these questions using a categorical question format (i.e. to select from several ranges of annual sales values). In instances where a categorical response was provided, the response value is assumed to be the mid-point of the range.

†The amount of grant funds awarded to one store (store 2 ) are not available.

Data summarises results from the seven stores who agreed to participate in this interview.

Values are reported as numbers unless otherwise indicated.

Table 3 Changes in monthly expenses and sales revenue on healthy foods by product category and store

\begin{tabular}{|c|c|c|c|c|c|c|}
\hline \multirow[b]{2}{*}{ Product } & \multicolumn{2}{|c|}{$\begin{array}{l}\text { Store purchases of items for } \\
\text { resale, by product }\end{array}$} & \multicolumn{2}{|c|}{ Store sales revenue by product } & \multirow[b]{2}{*}{$\begin{array}{l}\text { Products sell- } \\
\text { ing best }\end{array}$} & \multirow[b]{2}{*}{$\begin{array}{l}\text { Products not } \\
\text { selling well }\end{array}$} \\
\hline & $\begin{array}{l}\text { Baseline aver- } \\
\text { age (US\$) }\end{array}$ & $\begin{array}{l}\text { Change from } \\
\text { baseline (\%) }\end{array}$ & $\begin{array}{l}\text { Baseline aver- } \\
\text { age (US\$) }\end{array}$ & $\begin{array}{l}\text { Change from } \\
\text { baseline }(\%)\end{array}$ & & \\
\hline Low-fat Dairy & $155 \cdot 96$ & $6.9 \% *$ & $17 \cdot 59$ & $66.7 \%$ & $\begin{array}{l}\text { None } \\
\quad \text { reported }\end{array}$ & Milk \\
\hline Whole Milk & $196 \cdot 42$ & $73.9 \%$ & $26 \cdot 08$ & $2.8 \%$ & Milk & Milk \\
\hline Whole Grains & $24 \cdot 74$ & $67.9 \%$ & $14 \cdot 28$ & $40 \cdot 0 \%$ & Wraps & Bread, wraps \\
\hline Protein & 1281.36 & $169.0 \%$ & 63.40 & $21.8 \%$ & Eggs, Nuts & Beans \\
\hline Fruit & $140 \cdot 61$ & $128.3 \% *$ & $60 \cdot 14$ & $58 \cdot 3 \%$ & $\begin{array}{r}\text { Fruit Cups, } \\
\text { Bananas }\end{array}$ & None reported \\
\hline Vegetables & $38 \cdot 62$ & $-14.0 \%$ & $85 \cdot 39$ & $66 \cdot 1 \%$ & $\begin{array}{l}\text { Local, Fresh, } \\
\text { Frozen }\end{array}$ & Salads \\
\hline $100 \%$ Juice & $1206 \cdot 28$ & $716 \cdot 5 \% *$ & $66 \cdot 76$ & $167 \cdot 9 \% *$ & $\begin{array}{l}\text { None } \\
\text { reported }\end{array}$ & None reported \\
\hline \multicolumn{7}{|c|}{ Total store purchases and revenue, average across stores } \\
\hline Avg. of total sales changes & $2964 \cdot 81$ & $181.3 \%$ & $277 \cdot 64$ & $25.1 \%$ & & \\
\hline $\begin{array}{l}\text { Stores (number of monthly } \\
\text { reports submitted) }\end{array}$ & \multicolumn{2}{|c|}{ S3(5), S5(4), S8(14)† } & \multicolumn{2}{|c|}{ S1(9), S3(5), S6(8) } & & \\
\hline
\end{tabular}

*At least one store had not previously been carrying products in this category; given this baseline of zero expenses or sales, it was not possible to estimate a percentage change in sales or expenses for these stores. These stores were not included in the category average estimates.

†The baseline period varies by site depending on when their equipment was installed. Baseline purchase information not provided by store S8; change from baseline reflects data from stores S3, S5.

Storeowners identified products noted as selling well and not well. As their experienced varied, specific products could appear in both columns. 
Table 4 Impacts of and storeowner satisfaction of participating in the North Carolina Healthy Food Small Retailer Program

\begin{tabular}{|c|c|c|c|}
\hline Measure & Mean & SD & Range \\
\hline \multicolumn{4}{|l|}{ Level of difficulty or satisfaction* } \\
\hline Services provided by NCDA\&CS $†$ & 1.25 & 0.43 & $1-2$ \\
\hline Services provided by other local professionals $\dagger$ & 1.25 & 0.43 & $1-2$ \\
\hline Marketing efforts by NCDA\&CS $\dagger$ & 1.75 & 0.83 & $1-3$ \\
\hline Equipment for the healthy food items $\dagger$ & $2 \cdot 25$ & 1.09 & $1-4$ \\
\hline Difficulty in stocking healthier items $\dagger$ & 2.50 & $1 \cdot 12$ & $1-4$ \\
\hline \multicolumn{4}{|l|}{ Impact of HFSRP participation on business ${ }^{*}$} \\
\hline Agree resulted in an increase in overall salesł & 4.0 & & \\
\hline Agree sell more nutrient-dense foods $\ddagger$ & $5 \cdot 0$ & & \\
\hline \multicolumn{4}{|l|}{ Impact on customers ${ }^{*}$} \\
\hline Interested in learning more about healthy eating $\ddagger$ & 4.5 & & \\
\hline Satisfied with the new healthier options $\ddagger$ & $5 \cdot 0$ & & \\
\hline \multicolumn{4}{|l|}{ Programme impact and effectiveness§ } \\
\hline Healthy food supply score - annual changell & $2 \cdot 31$ & 1.84 & $0.75-5.25$ \\
\hline Healthy food supply score - investment effectiveness? & 0.12 & 0.11 & $0.03-0.31$ \\
\hline Healthy eating index - annual changell & $2 \cdot 51$ & 5.50 & $-2 \cdot 77-10.09$ \\
\hline Healthy eating index - investment effectiveness & $0 \cdot 10$ & 0.22 & $-0.11-0.41$ \\
\hline
\end{tabular}

NCDA\&CS, North Carolina Department of Agriculture \& Consumer Services; HFSRP, Healthy Food Small Retailer Program; HFS, Healthy Food Supply; HEI, Healthy Eating Index.

${ }^{*}$ These responses are drawn from all (five) respondents who completed the HFSRP Evaluation.

†Level of satisfaction and difficulty are measured using a five-point Likert scales; lower values indicate higher levels of satisfaction (very satisfied $=1$ ), lower level of difficulty (very easy $=1$ ).

†Responses are scored as: Yes (1), Somewhat (0.5), No (0).

§Data from the following stores were used in calculating the index scores: Healthy Food Supply Scores - S1, S3, S5, S6; Healthy Eating Index - S1, S2, S4, S5, S6.

IIAnnual change reflects the change in scores from a baseline period to 1 year after starting HFSRP participation.

qlnvestment Effectiveness is estimated as the change in HFS Score (or HEI) per US\$1000 HFSRP investment. The amount of grant funds awarded to one store (S2) are not available.

receiving this equipment due to the HFSRP. As several owners noted that they had encountered difficulty in getting loans, the programme offered an opportunity to acquire equipment they otherwise may not have been able to obtain. For some stores, dated equipment was replaced:

'My equipment had gotten older so a lot of the things that I'm able to do now, I wouldn't have been able to do because my equipment was just older, and it probably wouldn't support the salads and stuff like that.' [Owner, S6]

'I had some coolers that were older. So that brought the coolers up to date. It looks better. I have newer coolers and that just looks and keeps the food cooler and fresher longer than an old cooler would.' [Owner, S7]

For all other stores, the equipment was a new addition. In all cases, the storeowners felt that the equipment allowed them to expand the range of products they offered which, in turn, offered them financial and other benefits:

'I think any time you can offer more variety in a small store, even a convenience store, I think you're helping people be aware that you don't have to go to big grocery stores to get those things.' [Owner, S1]

'Has it been beneficial to us? Absolutely. We have a counter merchandise unit, we have a cooler and a freezer in the back, so it's been very helpful in...making it easier and more cost-efficient to serve the customers that we have. Good food that they can't get anywhere else.' [Owner, S4]
There were several unanticipated challenges with the HFSRP equipment. In almost all cases, storeowners reported waiting a considerable amount of time (6 months or more) after their acceptance into the HFSRP for their equipment to be delivered. In a few instances, store electrical wiring was outdated and new breaker boxes, wiring and/or outlets needed to be installed to accommodate the equipment; reimbursement of this expense by the HFSRP was permitted. Several owners also noted significant increases in electrical costs following the installation of new equipment. For two other stores, the equipment was damaged during installation or stopped working a short time thereafter; in these cases, the store was responsible for the repairs. Given this expense and difficulty getting the machines serviced in the rural areas where these stores are located, the equipment sat unused for a period of time in one case, and altogether stopped being used in the second. Food was wasted during these equipment failures (juice and milk spoiled) adding to the storeowner losses. Despite these challenges, however, all stores still in operation agreed that if the HFSRP equipment were removed they would feel the need to replace it.

\section{Stocking bealthier foods}

Most HFSRP storeowners reported that stocking healthier food options was between somewhat difficult and difficult (Table 4; mean rating $=2.5$ ). Interviews revealed that this was primarily due to storeowner confusion regarding which items qualified as healthy in the HFSRP, the logistical challenges of procuring healthy foods and challenges with spoilage and waste. Storeowners clearly wanted to abide 
by the spirit of the programme to stock healthy foods, but two expressed a need for more guidance regarding what qualified as healthy. As expressed by one owner:

'When we got the unit, we knew that we had to have healthy food in it. But it was like, "What is healthy food? Specifically, what is the criteria"?' [Owner, S3]

Storeowners reported devoting considerable time to doing their own research to identify 'healthy' foods and beverages; several sought guidance from NCDA\&CS programs (e.g. state fresh produce marketing programme) and local departments of public health.

Managing inventory of healthy foods, particularly fresh fruits, was also a challenge. Participating stores typically received deliveries once/week. If they sold out of healthy food items between deliveries, several storeowners reported that they purchased healthy items in standard grocery stores (at usual prices) for resale in their store. The need to do this occurred most frequently with fresh fruits. At the same time, storeowners also reported difficulty in keeping produce fresh and selling it before it spoiled. For example, when asked about challenges of participating in the programme, one owner stated:

'The only thing like I said is keeping the fruit good and the vegetables good, rotating them... When you buy it from those places, there's no taking it back... Once that money is out, it's out. If you don't sell it then it's just waste. It's wasted.' [Owner, S3]

During the interviews, storeowners were also asked about the amount of food that was wasted. For most stores, this amount was a relatively high percentage (mean $9 \%$; range 0\%-25\%) of their weekly healthy food purchases. One store reduced waste by using any products near expiration to make value-added products (e.g. apple pie). Storeowners identified this as a problem and reported seeking additional information on how to extend the shelf-life of these products from their HFSRP contacts.

\section{Working with healthy food suppliers}

Healthy foods and beverages stocked due to the HFSRP program were sourced from a wide variety of suppliers including local farms, grocery stores, warehouse stores and standard foodservice distributors. The approach and storeowner effort to obtain these foods also varied. Some storeowners reported driving considerable distances to procure healthy foods, while others only sourced healthy foods available from their existing suppliers.

Participating storeowners indicated that their experiences with their suppliers were positive overall and indicated that cost, variety, quality, past experience and convenience were the main consideration in their supplier selection. Six of the storeowners noted they made some effort to source products from local vendors. One owner explained factors affecting their supplier decisions as
'Cost, availability, and just really trying to push local because I think that when you keep it local, it helps the community overall.' [Owner, S6]

In addition, two of the owners reported that their use of some suppliers was constrained by minimum order requirements.

\section{Promoting bealthier foods to customers}

Most of the storeowners indicated that they had implemented efforts to promote healthier food choices among their customers as a result of HFSRP participation. Examples of the methods used to encourage healthier foods varied among storeowners; however, several cited the use of verbal encouragement:

'Just letting them be aware that they were available. A lot of times people don't take time to go in a store and really look around.' [Owner, S1]

Other examples of methods used to encourage healthier foods included offering samples, discounting healthy items and advertising. Related to advertising efforts, one owner shared:

'My husband did a TV interview ... About the healthy food section... We talked about food deserts and all these types of things. It was really good. Actually, from that of course, people posted on Facebook and shared it. We had people come just for that.' [Owner, S3]

In addition, stores linked their efforts to promote healthy foods to the foods which were locally in season:

'We encourage, we work really closely with [name withheld] about coming up with recipes or finding recipes of what it is that they're growing at the moment. So that's been good for us, good for our customers.' [Owner, S4]

Of those who did make an effort to promote healthier foods, most indicated that their efforts were successful. Importantly, a majority of storeowners agreed that their customers were interested in learning more about healthy eating, and all indicated that their customers were satisfied with the healthier food options they provided due to the HFSRP (Table 4).

\section{Healthy Food Small Retailer Program administration}

Storeowners were generally satisfied with the services provided through the HFSRP (mean rating 1.25 ) and efforts to promote the HFSRP (Table 4, mean rating 1.75). Marketing efforts included signage, food demonstrations and recommendations about how to effectively display healthy food products $^{(24)}$. A few administrative challenges of HFSRP participation were also identified. Some storeowners found the monthly financial reporting requirements to be burdensome. One owner relied on her daughter (who did not work at the store) to complete reports; she noted that this 
requirement would be less burdensome if the programme funds would have allowed them to purchase a computer. Other owners desired more general support such as knowing who to contact and receiving more ideas and feedback concerning how to implement the programme.

\section{Healthy Food Small Retailer Program impact and effectiveness}

A previous assessment of the HFSRP found that participation improved the HFS score (indicator of the healthy foods and beverages stocked in the store) and did not impact the HEI of participating store customers (indicator of the healthfulness of purchases in the store) relative to customers in control stores ${ }^{(16)}$. In the current analysis, the change in HFS and HEI scores are considered relative to the HFSRP investment in each store. As reported in Table 4, the current analysis indicates that, 1 year following implementation of the programme, participating store HFS scores improved by $2 \cdot 31$, and HEI index scores improved by 2.51 points. On average, an HFSRP investment of US $\$ 1000$ generated HFS and HEI score improvements of 0.12 and 0.10 , respectively.

Overall, a majority of stores agreed that participating in the HFSRP resulted in an increase in overall sales (Table 4). One storeowner highlighted this benefit in sharing:

'I feel like it's a good revenue stream for you. A different revenue stream. Especially because it's about the small retailers. I think it definitely brings another option in.' [Owner, S3]

The interviews revealed that, while most storeowners felt like they had gained a few new customers due to stocking healthier foods, more often owners reported that their customers changed the mix of products they bought. This was particularly true of breakfast customers and children. Several of the participating retailers are in rural locations and also served some prepared food such as breakfast sandwiches. Several storeowners noted that some customers now add a piece of fruit to their purchase. Multiple storeowners explicitly noted wanting to make healthier food options available to children:

'For me, I think that was one of the reasons why I really got involved because a lot of parents that they'll send their children to the store and they'll get a sweet cake and a soda. That's their supper. My thing is I wanted to make sure that when children come in, that they have other options besides that.' [Owner, S1]

\section{Discussion}

Our examination of factors affecting storeowner participation in the HFSRP identified several barriers and facilitators. Overall, the stores were grateful to have received equipment through the HFSRP, and all stores still in operation agreed that they would need to replace this equipment if it was removed. Most storeowners agreed that participating in the HFSRP increased their sales ( $n$ 4), and all agreed that their participation enabled them to sell more nutrient dense foods and beverages. Sales of $100 \%$ fruit juices, fruits and whole grains particularly increased among participating stores. A post-intervention evaluation of a corner store initiative in Baltimore, MD, also reported increased sales of nutrient-dense foods ${ }^{(15)}$. Also of note, overall, storeowners agreed that their customers were satisfied with their stock of healthier food and beverages and were interested in learning more about healthier eating. More detail and guidance on what was considered a healthy food or beverage was desired. Importantly, both the HFS and HEI scores had a positive change within 1 year of the programme implementation.

Overall, from the perspective of storeowners, the benefits to HFSRP participation would be enhanced if storeowners were provided additional support regarding what foods are considered 'healthy', which healthy foods and beverages to stock, inventory management and handling of perishable produce, and suggestions regarding where and how to best display these products within the store. There is already considerable marketing literature and best-practice information available on each of these items ${ }^{(31,32)}$. However, to be adopted by storeowners, this information would need to be made more widely available in a condensed and accessible format. In addition, there are several aspects of the HFSRP that were identified which could be improved, particularly related to the scope of permitted equipment, delivery and maintenance of equipment, and aspects of programme administration and reporting. Similar challenges related to identifying healthy foods ${ }^{(33)}$, tracking sales and inventory ${ }^{(33-35)}$, reporting requirements $^{(35)}$, scope of permitted equipment ${ }^{(36,37)}$, maintaining infrastructure ${ }^{(21,34)}$ and stocking healthy foods ${ }^{(20)}$ have been identified in previous studies evaluating efforts to improve healthy food access in small stores.

In considering the success and sustainability of HCS initiatives, consideration of the net financial benefits and other impacts of such programmes on participating stores is needed. Stores need to be provided adequate incentives to participate in such programmes, and state legislatures and other sponsoring organisations would benefit from specific feedback regarding programme features that could be adjusted to help improve and ensure their success. Related to this, Mah et al. ${ }^{(38)}$ reported success in engaging diverse stakeholders to form a collaborative research environment in which they were able to address evolving evidence throughout the intervention. The analysis presented herein offers a case examination of the HFSRP. However, the programme benefits, challenges, and recommendations are certainly relevant to similar programmes that are or could be offered in other jurisdictions.

While the current study offers a novel and first analysis of the financial benefits and barriers related to the HFSRP, 
additional data are needed to more completely inform policymakers. In particular, the requirement that stores report only store purchases or their sales revenue was problematic. Inconsistent reporting of business outcomes related to healthy food retail initiatives and the need for validated, reliable measurements to assess these outcomes has been previously noted, suggesting that this issue was not unique to the HFSRP ${ }^{(39)}$. At a minimum, it is necessary to collect information regarding both customer sales and stocking purchases at each store so that the profit margin (or loss) on sales of healthy food products by category can be calculated. To do so would likely require resources to encourage ongoing data collection. In light of the reporting efforts and hourly costs associated with the programme, an increase in the amount of award to participating stores and expansion of permitted uses of funds are suggested in order to offset the burden of requiring more detailed recordkeeping. Timely reporting is important, as recall and records become less certain and subject to error with time. As such, an end-of-programme or, for longer programmes, a mid-programme and an end-of-programme, bonus is also recommended for those stores who complete and submit all reports on time. Among other metrics, these data would enable estimates of the programme's impact on HEI and HFS scores to be generated over a longer period of time. Doing so would help address questions regarding whether such initiatives offer sustained benefits to corner store purchases, stocking patterns and, ultimately, customer's health.

Also, while beyond the scope of the current study, it is important to recognise that there is evidence from other areas that indicates that a greater percentage of corner store profits come from the sale of snack foods rather than from fruits and vegetables ${ }^{(40,41)}$. In cases where store space is limited and healthy food would replace other products on store shelves, there are additional revenue impacts that would need to be considered that may constrain the willingness of stores to participate in such a programme.

While the HFSRP seeks to improve healthy food access, implicitly this programme also benefits participating corner stores. Benefits of this programme could be further extended to the local community by facilitating efforts to purchase locally grown food, for example, through food hub programmes. As with many other similar programmes, the HFSRP does not currently have any guidelines or requirements concerning the source of the healthy foods sold by participating stores. Purchasing local foods can generate an economic multiplier through recirculating dollars spent on locally procured foods back into the local economy ${ }^{(42,43)}$. So as not to unduly burden the stores, such a requirement would need to be thoughtfully considered relative to the locally available healthy food, which can vary due to growing conditions and seasonality. For example, a HCS initiative might encourage sites to source a certain percent of fresh produce locally during the prime growing season. In the case of NC, this could be done in partnership with another local food programme, the NC $10 \%$ Campaign, which encourages NC individuals and food service operations (restaurants, institutions) to spend at least $10 \%$ of their food dollars on NC-grown foods. Further, the scope of the HFSRP and other such programmes could be expanded to offer some form of incentive, such as tax incentives or grants, to assist stores in stocking local products. In this way, the local agricultural community could also become a stakeholder and benefit financially from HCS initiatives. With additional supports and technical assistance, the positive benefits noted by HFSRP storeowners could be multiplied.

The barriers and challenges reported may inform potential approaches to ensuring success and sustainability of similar initiatives in other jurisdictions. However, the small sample size and consideration of a single geographic area (NC) are a consideration in generalising these findings to other settings. In addition, an important contribution of the current study is the consideration of investment effectiveness. As discussed above, our ability to more fully measure the financial impacts of the HFSRP was limited by the data available. This certainly could be improved in subsequent studies should reporting requirements be tailored to collect data need for this type of assessment. In doing so though, care would be needed to ensure that the overall reporting requirements are not too onerous and that store staff have the technical expertise and resources (e.g. funding for staff time, computer access) needed to efficiently collect and report this information.

Corner stores participating in the HFSRP experienced challenges related to equipment and healthy food procurement and aspects of HFSRP administration and reporting requirements. Overall, however, storeowners reported a net benefit from participating in this program. In addition, the current analysis found that the HFSRP generated a positive sales impact within each category of healthy food products and generated a positive impacts on HFS and HEI scores relative to investment in this programme. These benefits are generally consistent with those identified by HFSRP customers who reported that providing healthier foods and beverages in these stores did encourage them to make healthier purchase and consumption choices $^{(44)}$.

An important consideration in assessing the effectiveness of the HFSRP and health-promoting food-retail interventions are the programme benefits generated relative to the programme cost, when compared with alternative options of achieving the same public health outcomes. While a small number of recent studies have conducted economic evaluations food retailing and food service interventions ${ }^{(45)}$, these have examined settings outside of the US and have not been focused on small retailers. As there are no estimates of investment effectiveness of comparable programmes in the USA, it is not possible to assess the relative success of the HFSRP. Moving forward, the programme assessment approach developed herein, 
particularly consideration of changes in health outcome scores (HEI, HFS) relative to programme investment, may be adopted to offer additional metrics to assess other dimensions of programme outcomes.

\section{Conclusion}

While the current study offers a case study on the HFSRP, the findings may have important implications for the success and sustainability of similar programmes. To further support stores participating in such programmes, it would be helpful if additional guidance or resources concerning best procurement practices specific to corner stores could be made available. Several benefits were generated through participating in this programme. In evaluating store sales, it was found that HFSRP participation resulted in increases in their overall sales and provided stores the improved ability to stock and promote healthier food to customers. Indeed, importantly HFSRP participation was found to positively impact store-level HEI and HFS scores. From the perspective of storeowners, the HFSRP is a success and all would recommend to other storeowners that they participate. These results indicate that investments in the HFSRP and other similar programmes may positively impact both storeowner profits and the health of the surrounding community.

\section{Acknowledgements}

Acknowledgements: We wish to thank Madelyn Nolder for her assistance with this project. Financial support: Support for this article was provided by Policies for Action, a national programme of the Robert Wood Johnson Foundation, Grant Number: 76101. The views expressed here do not necessarily reflect the views of the Foundation. Conflict of interest: There are no conflicts of interest. Authorship: Conceptualisation and design of the study: K.A.B., S.B.J.P., A.S.A., L.H.M., J.T.M., K.P.T. and R.A.B. Data acquisition and/or analysis: K.A.B., E.V.F., J.T.M., C.J.K., V.E., N.S.J., S.J.B.P. and K.P.T. Results interpretation: All authors. Wrote the manuscript: K.A.B., E.V.F. Reviewed the manuscript for critical intellectual content: All authors. Read and approved the final version of the manuscript as submitted: All authors. Ethics of human subject participation: The current study was conducted according to the guidelines laid down in the Declaration of Helsinki, and all procedures involving research study participants were approved by the East Carolina University Institutional Review Board. Written informed consent was obtained from all participants in the in-depth interviews. Analysis of the programme evaluation data submitted to the NCDA\&CS was approved retrospectively.

\section{References}

1. Johnson JA III \& Johnson AM (2015) Urban-rural differences in childhood and adolescent obesity in the United States: a systematic review and meta-analysis. Child Obes 11, 233-241.

2. Befort CA, Nazir N \& Perri MG (2012) Prevalence of obesity among adults from rural and urban areas of the United States: findings from NHANES (2005-2008). J Rural Health 28, 392-397.

3. Lutfiyya MN, Lipsky MS, Wisdom-Behounek J et al. (2007) Is rural residency a risk factor for overweight and obesity for US children? Obesity 15, 2348-2356.

4. Garcia MC, Rossen LM, Bastian B et al. (2019) Potentially excess deaths from the five leading causes of death in Metropolitan and Nonmetropolitan counties - United States, 2010-2017. MMWR Surveill Summ 68, 1-11.

5. Powell LM, Slater S, Mirtcheva D et al. (2007) Food store availability and neighborhood characteristics in the United States. Prev Med 44, 189-195.

6. Ver Ploeg M, Breneman V, Farrigan T et al. (2009) Access to Affordable and Nutritious Food-Measuring and Understanding Food Deserts and Their Consequences: Report to Congress. U.S. Department of Agriculture, Economic Research Service. https://www.ers.usda.gov/ webdocs/publications/42711/12716_ap036_1_.pdf?v=5486. 2 (accessed September 2020).

7. Lutfiyya MN, Chang LF \& Lipsky MS (2012) A cross-sectional study of US rural adults' consumption of fruits and vegetables: do they consume at least five servings daily? $B M C$ Public Health 12, 280.

8. Almaguer Sandoval B, Law Y \& Young C (2014) Healthier Corner Stores: Positive Impacts and Profitable Changes. Philadelphia, PA, USA: The Food Trust; available at http:// thefoodtrust.org/uploads/media_items/healthier-cornerstores-positive-impacts-and-profitable-changes.original.pdf (accessed September 2020).

9. McGuirt JT, Jilcott Pitts SB, Ammerman A et al. (2015) A mixed methods comparison of urban and rural retail corner stores. AIMS Public Health 2, 554-582.

10. Kiszko K, Cantor J, Abrams C et al. (2015) Corner store purchases in a low-income urban community in NYC. J Community Health 40, 1084-1090.

11. Lent MR, Veur SV, Mallya G et al. (2015) Corner store purchases made by adults, adolescents and children: items, nutritional characteristics and amount spent. Public Health Nutr 18, 1706-1712.

12. Gittelsohn J, Rowan M \& Gadhoke P (2012) Interventions in small food stores to change the food environment, improve diet, and reduce risk of chronic disease. Prev Chronic Dis $\mathbf{9}$, 110015 .

13. Langellier BA, Garza JR, Prelip ML et al. (2013) Corner store inventories, purchases, and strategies for intervention: a review of the literature. Calif J Health Promot 11, 1-13.

14. National Center for Chronic Disease Prevention and Health Promotion \& Division of Nutrition, Physical Activity and Obesity (2011) State Initiatives Supporting Healthier Food Retail: An Overview of the National Landscape. Centers for Disease Control and Prevention. https://www.cdc.gov/ obesity/downloads/healthier_food_retail.pdf (accessed December 2019).

15. Song H, Gittelsohn J, Kim M et al. (2009) A corner store intervention in a low-income urban community is associated with increased availability and sales of some healthy foods. Public Health Nutr 12, 2060-2067.

16. Cavanaugh E, Green S, Mallya G et al. (2014) Changes in food and beverage environments after an urban corner store intervention. Prev Med 65, 7-12.

17. Jilcott Pitts SB, Wu Q, Truesdale KP et al. (2018) One-year follow-up examination of the impact of the North Carolina 
healthy food small retailer program on healthy food availability, purchases, and consumption. Int J Environ Res Public Health 15, 2681

18. Pitts SB, Bringolf KR, Lloyd CL et al. (2013) Formative evaluation for a healthy corner store initiative in Pitt County, North Carolina: engaging stakeholders for a healthy corner store initiative, part 2. Prev Chronic Dis 10, 120319.

19. Mayer VL, Young CR, Cannuscio CC et al. (2016) Perspectives of urban corner store owners and managers on community health problems and solutions. Prev Chronic Dis 13, 160172

20. Kim M, Budd N, Batorsky B et al. (2017) Barriers to and facilitators of stocking healthy food options: viewpoints of Baltimore city small storeowners. Ecol Food Nutr 56, 17-30.

21. Young S, DeNomie M, Sabir J et al. (2018) Around the corner to better health: a Milwaukee corner store initiative. $A m$ J Health Promot 32, 1353-1356.

22. North Carolina General Assembly (2015) Healthy Food Small Retailer/Corner Store Act (House Bill $250=$ S296). https://www.ncleg.gov/BillLookUp/2015/H250 (accessed September 2020).

23. Jilcott Pitts SB, Wu Q, Truesdale KP et al. (2017) Baseline assessment of a healthy corner store initiative: associations between food store environments, shopping patterns, customer purchases, and dietary intake in eastern North Carolina. Int J Environ Res Public Health 14, 1189

24. Fish R (2019) Healthy Food Small Retailer Project 2016-20172018-2019. https://www.ncagr.gov/markets/healthyFood SmallRetailer/documents/HealthyFoodSmallRetailer Report2019.pdf (accessed September 2020).

25. Rev (2020) Transcription - Audio Transcription Made Simple. https://www.rev.com/transcription (accessed September 2020).

26. Andreyeva T, Luedicke J, Middleton AE et al. (2012) Positive influence of the revised special supplemental nutrition program for women, infants and children food packages on access to healthy foods. J Acad Nutr Diet 112, 850-858.

27. Caspi CE, Lenk K, Pelletier JE et al. (2017) Food and beverage purchases in corner stores, gas-marts, pharmacies and dollar stores. Public Health Nutr 20, 2587-2597.

28. Guenther PM, Kirkpatrick SI, Reedy J et al. (2014) The healthy eating index-2010 is a valid and reliable measure of diet quality according to the 2010 dietary guidelines for Americans. J Nutr 133, 399-407.

29. Gunether PM, Casavale KO, Reedy J et al. (2013) Update of the healthy eating index: HEI-2010. J Acad Nutr Diet 113, 569-580.

30. Reedy J, Krebs-Smith SM \& Bosire C (2010) Evaluating the food environment: application of the healthy eating index2005. Am J Prev Med 38, 465-471.

31. US Fresh Fruit (2013) Basic Training - General Fruit Handling for Produce Managers. http://www.usfreshfruit.com/pdf/ produce_staff.pdf (accessed September 2020).
32. The Food Trust (2020) The National Healthy Corner Stores Network. http://thefoodtrust.org/administrative/healthycorner-stores-network (accessed September 2020).

33. Sadeghzadeh CJ, Soldavini J, Uslan D et al. (2020) Novel sales tracking method to evaluate a healthy corner store intervention. Health Promot Pract 21, 401-409.

34. Gittelsohn J, Laska M, Karpyn A et al. (2014) Lessons learned from small store programs to increase healthy food access. Am J Public Health 38, 307-315.

35. Paluta L, Kaiser ML, Huber-Krum S et al. (2019) Evaluating the impact of a healthy corner store initiative on food access domains. Eval Program Plann 73, 24-32.

36. Ayala GX, Baquero B, Laraia BA et al. (2013) Efficacy of a store-based environmental change intervention compared with a delayed treatment control condition on store customers' intake of fruits and vegetables. Public Health Nutr 16, 1953-1960.

37. Baquero B, Linnan L, Laraia BA et al. (2014) Process evaluation of a food marketing and environmental change intervention in tiendas that serve Latino immigrants in North Carolina. Health Promot Pract 15, 839-848.

38. Mah CL, Minaker LM, Jameson K et al. (2017) An introduction to the healthy corner store intervention model in Canada. Can J Public Health 108, e320-e324.

39. Blake MR, Backholer K, Lancsar E et al. (2019) Investigating business outcomes of healthy food retail strategies: a systematic scoping review. Obes Rev 21, 1394-1399.

40. Bodor JN, Ulmer VM, Dunaway LF et al. (2010) The rationale behind small food store interventions in low-income urban neighborhoods: insights from New Orleans. J Nutr 140, 1185-1188.

41. Minaker LM, Lynch M, Cook BE et al. (2017) Exploring sales data during a healthy corner store intervention in Toronto: the food retail environments shaping health (FRESH) project. Health Promot Chronic Dis Prev Can 37, 342-349.

42. Hughes DW \& Boys KA (2015) What we know and don't know about the economic development benefits of local food systems. Choices 30, 1-6.

43. Thilmany McFadden D, Conner D, Deller S et al. (2016) The Economics of Local Food Systems: A Toolkit to Guide Community Discussions, Assessments, and Choices. U.S. Department of Agriculture, Agricultural Marketing Service. https://www.ams.usda.gov/sites/default/files/media/ Toolkit\%20Designed\%20FINAL\%203-22-16.pdf (accessed September 2021)

44. Haynes-Maslow L, Jilcott Pitts SB, Boys KA et al. (2021) Qualitative perspectives of the North Carolina healthy food small retailer program among customers in participating stores in food deserts. BMC Public Health 21, 1459.

45. Tran HNQ, McMahon E, Moodie M et al. (2021) A systematic review of economic evaluations of health-promoting food retail-based interventions. Int J Environ Res Public Health 18, 1356. 